\title{
Design and Build a Motorcycle Security Controller Using the IoT-Based GPS Tracking Method
}

\section{Rancang Bangun Alat Pengendali Keamanan Sepeda Motor Menggunakan Metode GPS Tracking Berbasis IoT}

\author{
Afif Dimyati $^{1}$, Arif Wisaksono ${ }^{2}$, Dwi Hadidjaja Rasjid ${ }^{3}$ \\ \{afif.dimyati0@gmail.com ${ }^{1}$ \}
}

Program Studi Teknik Elektro, Fakultas Sains dan Teknologi, Universitas Muhammadiyah Sidoarjo

\begin{abstract}
Abstrack. Motor vehicle theft cases still often occur around us, this happens because there is still a lack of security systems in motorized vehicles that only use ignition keys and key covers, where weaknesses in standard security systems like this have been understood by motor vehicle theft perpetrators. to do the action. To overcome this, a motorized vehicle security system was created using the IOT-based GPS tracking method to prevent and make it easier to retrieve a stolen motorized vehicle. So far, most motorcycle safety devices are still physically secure, for example a solution commonly used by motorized vehicle owners by adding safety locks to discs, chaining and so on, but owners often forget to install locks, or vehicle alarms. The result of this research is the production of a controller design tool, motorcycle safety and GPS tracking to provide information on the last location of motorized vehicles and can control remotely based on iot. which has been experienced by motorized vehicle users.
\end{abstract}

Keywords - Motorcycle; Security; Control

\begin{abstract}
Abstrak. Kasus pencurian kendaraan bermotor masih seringkali terjadi di sekitar kita, hal ini terjadi karena masih kurangnya sistem keamanan yang terdapat pada kendaraan bermotor yang hanya menggunakan kunci kontak dan penutup kunci saja, yang dimana kelemahan sistem keamanan standar seperti ini telah dipahami oleh para pelaku pencurian kendaraan bermotor untuk melakukan aksinya. Kebutuhan akan sistem pengamanan tambahan dirasa sangat perlu, guna menghindari terjadinya pencurian kendaraan bermotor. Untuk mengatasi itu semua maka dibuatlah sistem keamanan kendaraan bermotor menggunakan metode gps tracking berbasis IOT untuk mencegah dan mempermudah mendapatkan kembali kendaraan bermotor yang telah dicuri. Sejauh ini, alat pengaman sepeda motor kebanyakan masih bersifat pengamanan secara fisik, misalnya solusi yang biasa dilakukan oleh pemilik kendaraan bermotor dengan menambah kunci pengaman di cakram, dirantai dan lain sebagainya tetapi pemilik sering lupa memasang kunci, atau alarm kendaraan.Apalagi pencuri kendaraan bermotor dapat membuat kuncikunci duplikat sehingga pencuri kendaraan bermotor bisa dengan santai melakukan aksinya dengan tidak mengundang kecurigaan.
\end{abstract}

Kata Kunci - Sepeda motor; Keamanan; Pengendalian

\section{PENDAHULUAN}

Kendaraan bermotor sangat mudah di temui di kota bahkan sudah merambah ke pedesaan serta pulau-pulau kecil di Indonesia [1]. Walaupun kendaraan bermotor termasuk barang mewah, namun sebagian besar masyarakat Indonesia merasa perlu memiliki kendaraan bermotor untuk mempermudah aktivitas di luar rumah [2]. Semakin tingginya daya beli masyarakat terhadap kendaraan bermotor dan minimnya pengamanan membuat tingkat pencurian bermotor semakin meningkat [3]. Beberapa faktor penyebab terjadinya kasus pencurian antara lain, pengaruh pergaulan dalam lingkungan, kebutuhan ekonomi yang mendesak dan tingkat kebutuhan yang tinggi serta kelalaian korban atau pemilik motor yang menghiraukan penambahan alat pengaman pada kendaraannya menjadi alasan untuk munculnya tindak kriminalitas tersebut [4].

Kasus pencurian kendaraan bermotor masih seringkali terjadi di sekitar kita, hal ini terjadi karena masih kurangnya sistem keamanan yang terdapat pada kendaraan bermotor yang hanya menggunakan kunci kontak dan penutup kunci saja, yang dimana kelemahan sistem keamanan standar seperti ini telah dipahami oleh para pelaku pencurian kendaraan bermotor untuk melakukan aksinya [5]. Kondisi tersebut mengharuskan pemilik kendaraan bermotor untuk lebih memperhatikan keamanan kendaraannya. Sistem pengamanan yang baik sangat dibutuhkan pada kendaraan bermotor [6]. 


\section{II.METODE}

\section{A. Prosedur penelitian}

Metode penelitian yang digunakan dalam penelitian ini secara umum tersusun sebagai berikut :

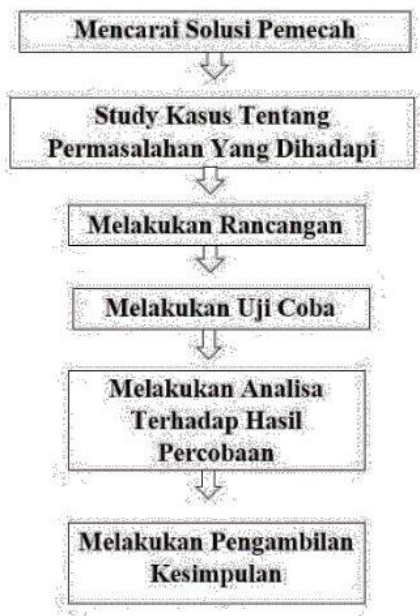

Gambar 1. Flowchart Prosedur Penelitian

\section{B. Teknik analisis}

Dalam Penelitihan SKRIPSI, diterapkan beberapa langkah kerja / metode penelitian yang meliputi :

Observasi / survei lapangan

Pengamatan secara langsung terhadap permasalahan maupun alur kerja sehingga di dapat data yang otentik dan informasi yang jelas [7]. Pengamatan ini dilakukan di rumah saya sendiri kemudian sepeda motor di tempatkan ditempat yang dirasa cukup aman [8].

\section{Study kepustakaan}

Mencari informasi dan refrensi melalui internet, serta membaca buku yang berhubungan dengan teknologi IOT (Internet of things) dan pengaman sepeda motor sehingga dapat lebih memahami permasalahan yang dihadapi dalam memecahkan masalah tersebut [9].

\section{Analisa permasalahan}

Melakukan analisa terhadap permasalahan sepeda motor guna menentukan batasan-batasan dalam menyelesaikan masalah agar lebih efisien, beserta metode pengolahan data penelitian meliputi nilai rata-rata pengujian sensor dan alat serta standart akurasi sensor yang digunakan [10].

Dari permasalahan tersebut bagaimana cara agar mendapatkan suatu keamanan dengan rancangan bangun yang mampu memberikan pemantauan terhadap kendaraan sepeda motor.

\section{HASIL DAN PEMBAHASAN}

\section{A. Pengujian alat}

Pengujian ini dilakukan untuk mengetahui kinerja dari alat untuk mengetahui apakah perangkat sudah sesuai dengan apa yang diinginkan perencanaan atau belum. Pengambilan dan pengujian alat dilakukan tiap bagian sistem serta dilakukan pengujian sistem secara keseluruhan. Adapun pengujian alat yang dilakukan sebagai berikut :

1. Pengujian mikrokontroler NodeMCU.

2. Pengujian Relay

3. Pengujian Sensor Proximity

4. Pengujian transfer data Iot

\section{B. Pengujian mikrokontroler nodemcu}

Mikrokontroler NodeMCU dapat diuji dengan program dan rangkaian sederhana [11]. Program dan rangkaian 
yang dibuat untuk memastikan semua pin pada mikrokontroler masih berfungsi [12]. Program pengujian yang paling sederhana dapat menggunakan program untuk menyalakan led [13].

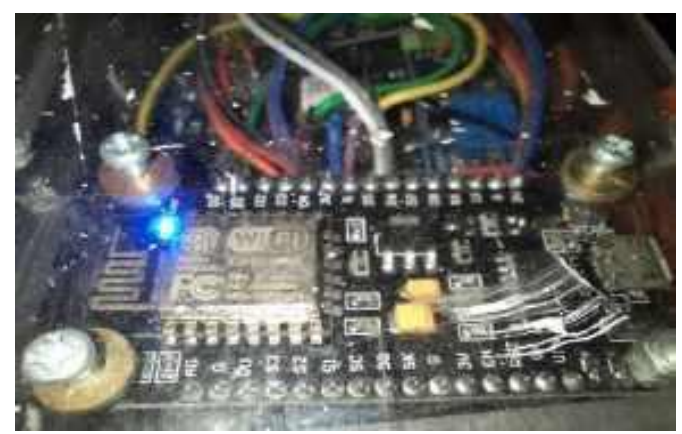

Gambar 2. Pengujian Mikrokontroler NodeMCU

Dengan tahapan dan prosedur instalasi pada PC dengan menggunakan aplikasi Arduino IDE versi 1.8.9 berikut prosedur yang harus dijalankan [14]:

1. Sambungkan NodeMCU dengan komputer yang telah terinstal aplikasi Arduino IDE dengan mengunakan kabel USB.

2. Pastikan port yang digunakan telah sesuai dengan posisi port yang terdeteksi pada komputer, dengan cara membuka device manager dan memilih posisi port kabel USB.

3. Sesuai port yang ada pada program Arduino IDE klik tools, kemudian pilih port yang sesuai pada gambar 3

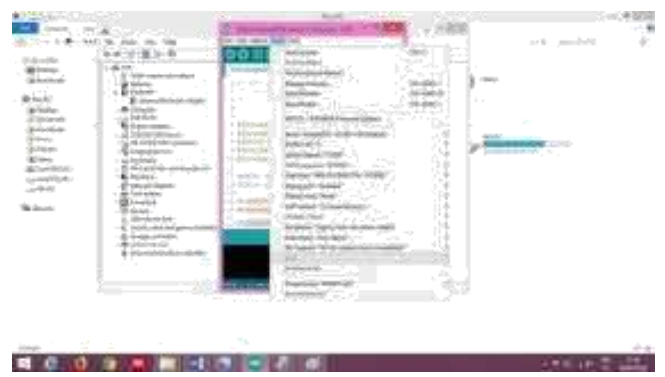

Gambar 3. Setting program pada program Arduino IDE

4. Kemudian sesuai board yang ada pada program Arduino IDE dengan cara klik tools, kemudian pilih board sesuai Arduino yang digunakan NodeMCU, seperti gambar 3

5. Kemudian klik icon (file-examples-Blynk-Boards_WiFi- NodeMCU) fungsi tersebut untuk mengetahui apakah NodeMCU masih bekerja dengan baik atau tidak. Program blynk bekerja pada kaki NodeMCU D5

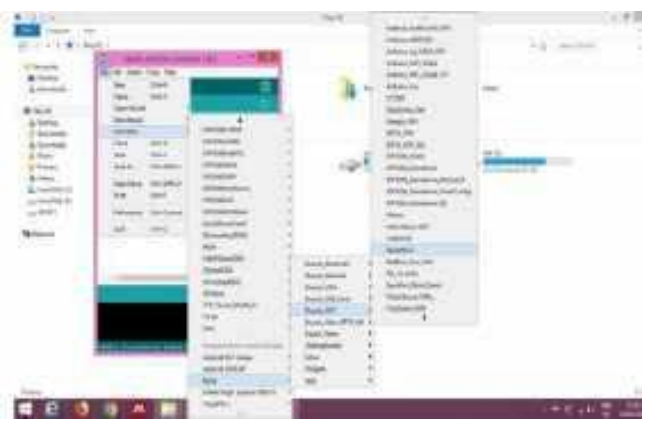

Gambar 4. Setting program pada program Arduino IDE

\section{Pengujian relay}

Relay akan diuji dengan menggunakan tegangan 5volt yang pengujinnya menggunakan AVO meter [15]. Jika 
kontak pada Relay yang posisi awalnya NO (Normally Open) tersambung dengan NC ( Normally Close) Relay mati,maka relay tersebut normal layak digunakan.

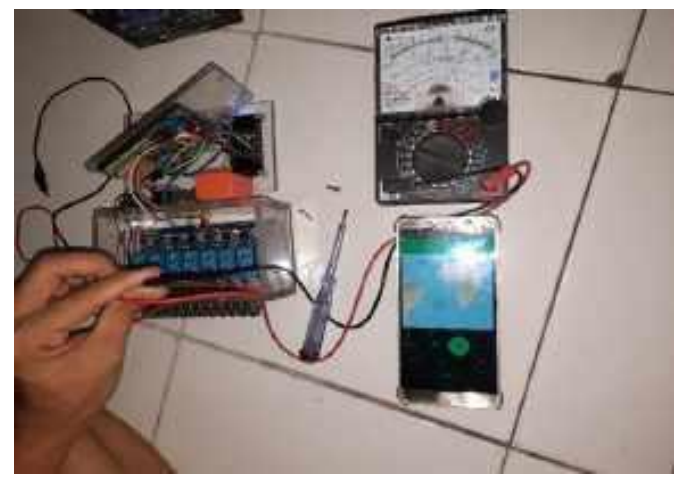

Gambar 5. Pengujian Relay

Gambar 5 koneksi pada kontak relay NO (Normally Open) pada saat pengujian tidak terkoneksi NC (Normally Close) pada relay terhubung, maka relay tersebut rusak tidak layak untuk digunakan.

\section{Pengujian sensor proxymity sebagai alarm}

Pengujian sensor Proxymity ini dilakukan untuk mengetahui apakah kemudian sepeda motor mengalami pergerakan atau tidak, yang difungsikan sebagai alarm sepeda motor saat kendaraan terparkir [16]. Langkahlangkah dalam perakitan dan pengujian sensor Proximity sebagai alarm adalah sebagai berikut :

1. Sensor Proximity mempunyai tiga kabel yang berbeda warnanya yang terdiri dari warna BN (Brown), BK (Black),BU (Blue) dan masing- masing warna kabel memiliki fungsi sebagai berikut :

-BN (Brown) sebagai inputan tegangan+12volt

-BK (Black) sebagai outputan dari BN (Brown)

-BU (Blue) sebagai tegangan -12volt

2. Sambungkan kabel BN (Brown) pada pin common relay sedangkan pin NO (Normally open) relay disambungkan pada sumber Aki tegangan 12volt, sedangkan kabel BK (Black) dari output sensor proximity langsung di sambungkan ke klakson sepeda motor, untuk kabel BU (blue) sensor proximity langsung menuju Aki - 12 volt

3. Hubungkan pin modul relay menuju ke pin mikrokontroller NodeMCU dan sambungkan juga pin vec dan gen pada modul relay menuju catu daya

4. Hubungkan microkontroller NodeMCU dengan komputer menggunakan kabel USB

5. Selajutnya aktifkan komputer dan jalankan program Arduino IDE

6. Upload program kedalam microkontroller NodeMCU

7. Aktifkan buttom alarm pada aplikasi smartphone dan hubungkan jaringan kepada mikrokontroller NodeMCU

8. Jika sensor proximity bekerja power led akan menyala warna Kuning

9. Jika sensor proximity terhalang benda maka led menyala warna Orange

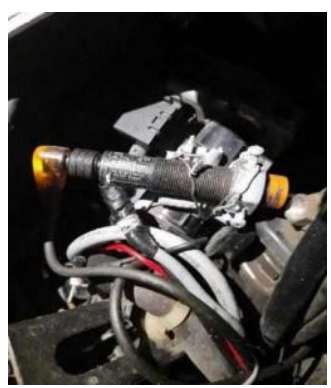

Gambar 6. Penempatan Sensor Proximity 
Tabel 1. Pengujian Sensor Proximity

\begin{tabular}{|c|c|c|c|c|c|c|}
\hline \multirow{2}{*}{ NO } & \multirow{2}{*}{$\begin{array}{c}\text { Jarak } \\
\end{array}$} & \multicolumn{3}{|c|}{ Data Terkirim } & \multirow{2}{*}{$\begin{array}{c}\text { Rata- } \\
\text { Rata }\end{array}$} & $\begin{array}{c}\% \\
\text { Error }\end{array}$ \\
\cline { 3 - 5 } & 0,5 & 1 & 1 & 1 & 1 & $0 \%$ \\
\hline 1 & 1 & 1 & 1 & 1 & 1 & $0 \%$ \\
\hline 2 & 1 & 1 & 1 & 1 & 1 & $0 \%$ \\
\hline 3 & 1,5 & 1 & 1 & 1 & 1 & $0 \%$ \\
\hline 4 & 2 & 1 & 1 & 1 & 1 & $0 \%$ \\
\hline 5 & 2,5 & 1 & 1 & 1 & 1 & $0 \%$ \\
\hline 6 & 3 & 1 & 1 & 1 & 1 & $0 \%$ \\
\hline 7 & 3,5 & & 1 & & 1 & $100 \%$ \\
\hline 8 & 4 & 0 & 0 & 0 & 0 & \\
\hline
\end{tabular}

Keterangan tabel:

P1 : Percobaan Pertama P2 : Percobaan Kedua P3 : Percobaan Ketiga

\section{$1:$ Terkirim}

$$
\begin{aligned}
& 0 \text { : Tidak Terkirim } \\
& \text { Rumus Rata-Rata } \begin{array}{c}
\% \text { Error }=\mid \text { 1-Rata-Rata Berhasil } \\
\times 100 \%
\end{array} \\
& 1 . \% \text { Error }=|1-1| \times 100 \%=0 \times 100 \%=0 \% \\
& 2 . \% \text { Error }=|1-1| \times 100 \%=0 \times 100 \%=0 \% \\
& 3 . \% \text { Error }=|1-1| \times 100 \%=0 \times 100 \%=0 \% \\
& 4 . \% \text { Error }=|1-1| \times 100 \%=0 \times 100 \%=0 \% \\
& 5 . \% \text { Error }=|1-1| \times 100 \%=0 \times 100 \%=0 \% \\
& 6 . \% \text { Error }=\mid 1-\underset{100 \%}{\mid x} 100 \%=0 \times=0 \% \\
& 7 . \% \text { Error }=\mid 1-\underset{100 \%}{\mid} \times 100 \%=0 \times=0 \% \\
& 0 \\
& 8 . \% \text { Error }=\mid 1-\underset{100 \%}{\mid x} 100 \%=1 \times \quad=100
\end{aligned}
$$

\section{E. Pengujian instalasi aplikasi blynk ke smartphone android}

Untuk menguji sebuah Smartphone Android Aplikasi yang di gunakan adalah Blynk - IoT for Arduino, ESP8266/32, Respberry Pi, Aplikasi ini kompatibel dengan semua versi Android. Dalam pengujian ini menggunakan Smartphone Android Samsung Galaxy Note 5 (versi Lolipop) yang digunakan untuk proses pengujian pada tahapan selanjutnya, berikut adalah langkah - langkah dalam instalasi aplikasi:

1. Menginstal aplikasi Blynk - IoT for Arduino, ESP8266/32, Respberry Pi di Google play store.

2. Buka aplikasi Blynk - IoT for Arduino, ESP8266/32, Respberry Pi pilih sign up akun baru atau login menggunakan alamat Facebook.

3. Buat projek baru, dan pilihlah salah satu module yang akan dipergunakan dan aksesoris module yang berfungsi sebagai sarana terhubung ke internet

4. Setelah itu drag dan drop rancangan projek yang sudah dibuat.

5. Kemudian klik atau buka Blynk untuk mengirim token Auth melaui alamat email.

6. Dan terakhir cek inbox atau pesan di email anda dan temukan Auto token yang dimana ini akan di pergunakan untuk program yang di download ke module. 


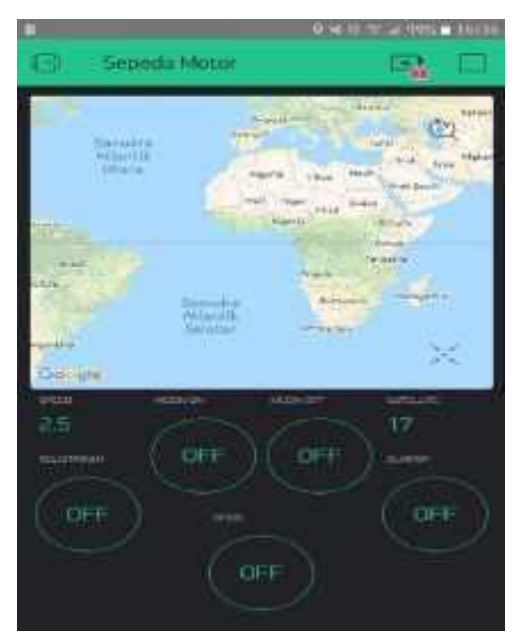

Gambar 7. Tampilan Aplikasi Blynk Pada Smartphone Android

\section{F. Pengujian koneksi wifi pada smartphone android samsung galaxy note 5 (versi lolipop).}

Pengujian koneksi Wifi dengan android Smartphone Samsung Galaxy Note 5 (versi Lolipop), dimana jaringan wifi pada Smartphone dan aplikasi Blynk sudah siap untuk dijalankan sebagai remot kontrol pengendali Sepeda motor dengan aplikasi Blynk.

Tabel 2. Percobaan Transfer data Iot (Internet of things)

\begin{tabular}{|c|c|c|c|c|c|c|c|c|c|}
\hline \multirow[b]{2}{*}{ No } & \multirow[b]{2}{*}{ Jarak } & \multirow[b]{2}{*}{ Percobzan } & \multicolumn{2}{|c|}{ TOMEOL } & \multirow[b]{2}{*}{ Longitude } & \multirow[b]{2}{*}{ Latitude } & \multirow[b]{2}{*}{ Speed } & \multirow[b]{2}{*}{ Satellite } & \multirow[b]{2}{*}{ Lokasi } \\
\hline & & & Alaram & $\begin{array}{l}\text { Koutak \& } \\
\text { Kelistrkan }\end{array}$ & & & & & \\
\hline \multirow{3}{*}{ I } & $\begin{array}{l}5,9 \\
\mathrm{Km}\end{array}$ & 1 & on & on & 112.783882 & -7.598432 & 28.3 & 28 & $\begin{array}{l}\text { Rumah-y } \\
\text { Alum-Alum } \\
\text { Bungil }\end{array}$ \\
\hline & $\begin{array}{l}12 \\
\mathrm{Km}\end{array}$ & 2 & on & On & 112.699959 & -7.666511 & 25.59 & 15 & $\begin{array}{l}\text { Allum-Alun } \\
\text { Baggil-s } \\
\text { Taman Dayu } \\
\text { Foodcourt }\end{array}$ \\
\hline & $\begin{array}{l}2,6 \\
\mathbb{K} \text { 列 }\end{array}$ & 3 & on & On & 112.687912 & -7.652158 & 26.59 & 189 & $\begin{array}{l}\text { Tuman Dayu } \\
\text { Foodcourt - } \\
\text { Nasjid } \\
\text { Musaramad } \\
\text { Cheng Hoo }\end{array}$ \\
\hline \multirow{3}{*}{2} & $\begin{array}{l}15 \\
\mathrm{Km}\end{array}$ & 1 & on & on & 112.695168 & -7.539118 & 13.2 & 12 & $\begin{array}{l}\text { Masjid } \\
\text { Munamand } \\
\text { Cheng Hoo. } \\
\text { > Terminal } \\
\text { Porong }\end{array}$ \\
\hline & $\begin{array}{c}18 \\
\mathrm{Km}\end{array}$ & 2 & on & on & 112.718597 & -7.446654 & 31.76 & II & $\begin{array}{l}\text { Terminal } \\
\text { Porong-s } \\
\text { Allun-Alun } \\
\text { Siloarjo }\end{array}$ \\
\hline & $\begin{array}{l}2,6 \\
\mathrm{Km}\end{array}$ & 3 & on & On & $112.71659 \mathrm{l}$ & -7.4668 & 49.12 & 19 & 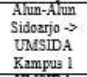 \\
\hline \multirow{3}{*}{3} & $\begin{array}{l}16 \\
\mathrm{Km}\end{array}$ & 1 & on & on & 112.698746 & -7.543256 & 38.61 & 53 & $\begin{array}{l}\text { UNSiDA } \\
\text { Kampus I-3 } \\
\text { Pusdik } \\
\text { Sabare }\end{array}$ \\
\hline & $\stackrel{9}{\mathrm{~K} m}$ & 2 & on & On & 112.735222 & -7.580831 & 46.41 & 33 & 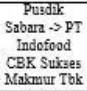 \\
\hline & $\begin{array}{l}2,4 \\
\mathrm{Km}\end{array}$ & 3 & on & On & 112.739591 & -7.577371 & 0.99 & $?$ & $\begin{array}{l}\text { PTIndofood } \\
\text { CBR Sukses } \\
\text { Makmur Tok } \\
\rightarrow \text { Rumah }\end{array}$ \\
\hline
\end{tabular}




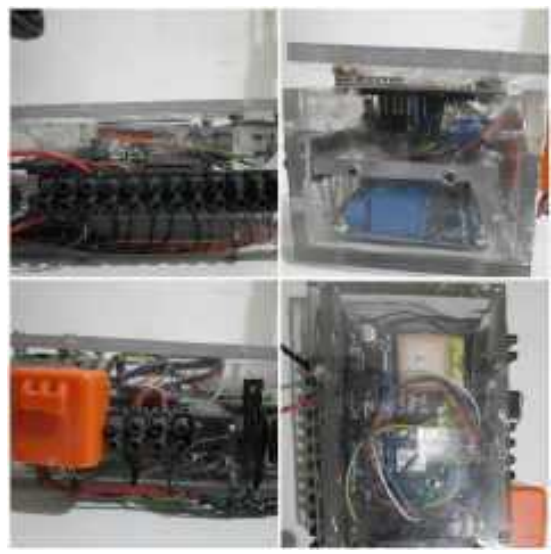

Gambar 8. Tampilan Alat Pengendali Keamanan Sepeda Motor

Pada pengujian alat ini ada langkah-langkah pengujian yang dilakukan sebagai berikut :

1. Koneksikan kabel kelistrikan yang ada disepeda motor dengan terminal yang ada pada alat pengendali kelistrikan sepeda motor.

2. Menyalakan saklar ON /OFF yang ada pada alat pengendali kelistrikan sepeda motor untuk memberi arus tegangan pada alat tersebut.

3. Menyiapkan wifi dan Smartphone android.

4. Memulai jalankan program dengan membuka aplikasi Blynk pada Smartphone android

5. Catat hasilnya

\section{KESIMPULAN}

Berdasarkan hasil pengujian dan pembahasan dapat disimpulkan yakni (1) Telah terealisasi sebuah sistem kontrol keamanan pada kendaraan roda dua dengan memanfaatkan koneksi IOT (Internet Of Things) pada Smartphone yang dapat mengontrol kendaraan yang dalam jarak jauh; (2) Telah terealisasi sebuah sistem kontrol keamanan pada kendaraan roda dua dengan memanfaatkan modul GPS yang dapat memantau letak keberadaan kendaraan dari jarak jauh. (3) Telah terealisasi sebuah rancangan alat pengendali keamanan pada kendaraan roda dua dengan memanfaatkan alarm yang disambungkan dibagian kemudi sepeda motor, sehingga saat terjadi gerakan pada kemudi sepeda motor alarm akan menyalah dan berbunyi. (4) Pada penelitian ini modul GPS mampu mendapat kan koordinat dengan selisih rata -rata 4 meter dari GPS Smartphone pengguna. (5) Sistem kontak bekerja dengan baik saat digunakan untuk menyalakan sepeda motor.

\section{REFERENSI}

[1] Majdah Zawawil and Noriah Ramli, No Title'국회선진화법, 에 관한 보론, vol. 제13집 1호, no. May. 2016.

[2] D. Menggunakan, S. M. S. Berbasis, dan A. Mega, "No Title," 2018.

[3] J. Dipatiukur, N. Bandung, dan J. Barat, "Pembangunan Sistem Keamanan Sepeda Motor Menggunakan Gps Tracking Dan Kunci Kontak Pintar Berbasis Mikrokontrol er Arduino.”

[4] H. Fitriyah dan G. E. Setyawan, "Sistem Pemantauan Menggunakan Blynk dan Pengendalian Penyiraman Tanaman Jamur Dengan Metode Logika Fuzzy,” vol. 3, no. 4, 2019.

[5] E. D. Marindani dan B. W. Sanjaya, "Rancang Bangun Sistem Peringatan Dini Da n Pelacakan Pada Kendaraan Sepeda Motor Dengan Menggunakan Mikrokontroler Arduino Nano,” J. Elektro, hal. 1-11, 2014.

[6] P. Akhir et al., "Bermotor Dengan Fasilitas Missedcall Berbasis Bermotor Dengan Fasilitas Missedcall Berbasis," 2012.

[7] L. Hakim, "MENGGUNAKAN SMS BERBASIS MIKROKONTROLER AVR ATMega8535," 2009.

[8] P. Berbasis dan M. Avr, "No Title," no. Diii, 2011.

[9] A. Wisaksono, "Design of Monitoring and Control of Energy Use in Multi - storey Buildings based on IoT Rancang Bangun Monitoring dan Pengendalian Penggunaan," vol. 4, no. 2, hal. 2019- 2020, 2020. 1385.

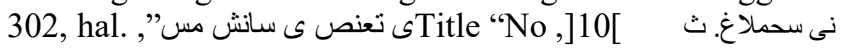


Procedia of Engineering and Life Science Vol. 1. No. 1 March 2021

Seminar Nasional \& Call Paper Fakultas Sains dan Teknologi (SENASAINS 1st)

Universitas Muhammadiyah Sidoarjo

[11] B. A. B. Ii dan C. Ethnocentrism, "Bab ii landasan teori 2.1," hal. 14 -31, 1987.

[12] A. P. A, "Internet of Things - Rfid Sebagai Pendukung Lampu Lalu Lintas," hal. 1-10.

[13] Y. Efendi, "Internet of Things ( Iot ) Sistem Pengendalian Lampu," J. Ilm. ilmu Komput., vol. 4, no. 1, hal. 19-26, 2018

[14] B. A. B. Ii dan T. Pustaka, “(Anonim a, 2012),” 2012.

[15] P. Ilmiah, P. Studi, T. Elektro, F. Teknik, dan U. M. Surakarta, "Desain dan pembuatan alat pengaman sepeda motor dengan sistem kontrol arduino," 2016.

[16] P. D. A. N. Perawatannya, “Akumulator, pemakaian dan perawatannya,” vol. 11, no. 1, 2015 